\title{
Mechanical Engineering Capstone Design Course - CEAB Accreditation Outcomes Assessment
}

\author{
Jacqueline Stagner and Jennifer Johrendt \\ University of Windsor
}

\begin{abstract}
Due to the comprehensive nature of the twosemester Capstone Design course for fourth-year students, many of the Canadian Engineering Accreditation Board (CEAB) Graduate Attributes (GrAtts), and associated learning outcomes (LOs), are present within the course. As the term 'graduate attribute' implies, students should exhibit specific attributes upon graduation. Thus, assessing these attributes in the students' final year enables the faculty and students to verify that the goal of achieving these attributes has been accomplished. However, it is also necessary to examine the results of the assessments to make any downstream adjustments to the curriculum, to address any weaknesses in specific attributes.
\end{abstract}

The undergraduate course calendar provides the following course description for the Capstone Design course:

Student design teams, operating within $a$ "company" environment, utilize the broad range of their undergraduate experience in interdisciplinary projects selected to promote interaction between the mechanical, automotive, and materials programs. Design methodologies and team interaction simulate future professional practice. Project milestones include: a design proposal with cost analysis and scheduling, construction and commissioning of the designed apparatus, and a final report and presentation having both global and detail completeness [1].

One can see that the course is comprehensive; however, it is also quite unique for each design team as it pertains to each specific project. The uniqueness of projects, along with the fact that there are multiple advisors and assessors of projects, provides challenges to ensuring accurate and consistent assessments.

This paper will describe what the department of Mechanical, Automotive \& Materials Engineering (MAME) at the University of Windsor has incorporated into the Capstone Design course to assess many of the
CEAB GrAtts and LOs, and implement a continuous improvement program for the department.

\section{Keywords:}

CEAB Accreditation; Outcomes Assessment; Capstone Design Course

\section{INTRODUCTION}

The assessment of learning outcomes in higher education is performed in varying degrees around the world [2]. The general principle behind outcomes-based education is that it shifts the focus of curricula from an instructor-centred (e.g., the topics that will be covered) to a student-centred (e.g., what students should know, understand, perform, etc. by the end) domain. From the perspective of engineering accreditation in Canada, outcomes-based education ensures that undergraduate engineering programs provide the required education for licensure as a professional engineer in Canada [3].

One of the requirements for CEAB accreditation, starting with the 2014-2015 Accreditation Visit Cycle, includes demonstrating that graduates from undergraduate engineering programs possess twelve GrAtts [4]. The twelve attributes include; a knowledge base for engineering, problem analysis, investigation, design, use of engineering tools, individual and team work, communication skills, professionalism, impact of engineering on society and the environment, ethics and equity, economics and project management, and life-long learning. The learning outcomes associated with each course map to these twelve graduate attributes, ensuring a comprehensive education for every student. Assessment of learning outcomes enables instructors and departments to measure the effectiveness of individual courses and/or programs in achieving the necessary outcomes for future professional engineers. Improvements can then be made based on both student performance and the tools used to measure the performance [5]. This forms a framework for a continuous improvements process within the program.

In preparing for the new outcomes-based reporting of GrAtts for Canadian Engineering Accreditation Board (CEAB) accreditation at the 
University of Windsor, it became evident that many of the GrAtts are applied and assessed within the Capstone Design course in Mechanical, Automotive \& Materials Engineering. For this reason, detailed rubrics were developed for many of the assessment tasks required of the students. As well, these rubrics were used to track the students' achievement of the GrAtts. This paper will describe the process that was followed in undertaking the task of moving towards an outcomes-based course design, as well as the 'Lessons Learned' from this process.

\section{METHODOLOGY}

Students in their fourth year of study in MAME at the University of Windsor are required to complete a two-semester, Capstone Design course. The course starts during the Winter semester and finishes during the Summer semester. For the 2014 offering of the course, the course LOs were developed, the assessments that would demonstrate that students have achieved the LOs were identified, and these assessments were developed, along with the rubric for each assessment. A list of the LOs and associated modes of assessment are shown in Table 1. One can see that each of the course LOs focuses on a specific CEAB GrAtt and, consequently, eight GrAtts are being assessed through course activities, assignments, and projects.

As a result of the course assessing many of the GrAtts, easy-to-use grading rubrics were developed for each assessment task (i.e., letter of intent, progress report, presentation, etc.). These grading rubrics were designed to focus on the specific requirements of each task while also evaluating the students' ability to demonstrate their achievement of the associated LOs.

In developing the rubrics, an important consideration was that the rubrics would be used by the course coordinator, as well as the faculty advisors for the individual student project teams. The rubrics must provide enough description for each criteria and level of achievement that different evaluators would provide similar evaluations for the same assessment task. As well, the amount of detail should not be too great, as to be too time-consuming for evaluators to use and complete the assessment. As an example, the rubric for the Progress Poster Presentation assessment task is shown in Table 2. Evaluators were asked to circle one of the four ratings for each line item to indicate if they felt that the group failed, performed marginally, met, or exceeded the learning outcomes in each of the three assessed categories for this deliverable: design, individual and team work, and communication skills. It should be noted that the rubric indicators in Table 2 were taken from the University of Toronto attribute tables posted on the EGAD website, http://egad.engineering.queensu.ca/?page_id=1207 [6]. 
Table 1. MAME Capstone Design learning outcomes.

\begin{tabular}{|c|c|c|}
\hline $\begin{array}{l}\text { Course } \\
\text { Learning } \\
\text { Outcome }\end{array}$ & Description & Mode of Assessment \\
\hline 1 & $\begin{array}{l}\text { Problem analysis: The Capstone project process helps in training the } \\
\text { students on how to identify and characterize an engineering problem, } \\
\text { formulate a solution plan (methodology) for an engineering problem } \\
\text { and execute a solution process for an engineering problem. }\end{array}$ & $\begin{array}{l}\text { Letter of Intent, Group Written } \\
\text { Final Report }\end{array}$ \\
\hline 2 & $\begin{array}{l}\text { Investigation: While completing a Capstone project, students will learn } \\
\text { how to define a problem, devise and execute a plan to solve a problem. } \\
\text { To this end, critical analyses are used to reach valid conclusions } \\
\text { supported by the results of the plan. }\end{array}$ & Group Written Final Report \\
\hline 3 & $\begin{array}{l}\text { Design: Since the Capstone projects consist of complex open ended } \\
\text { problems in engineering terms, the students will generate a diverse set } \\
\text { of candidate engineering design solutions, select the candidate } \\
\text { engineering solutions for further development, and then advance an } \\
\text { engineering design to a defined end state. }\end{array}$ & $\begin{array}{l}\text { Progress Poster Presentation, } \\
\text { Group Written Progress } \\
\text { Report, Group Written Final } \\
\text { Report }\end{array}$ \\
\hline 4 & $\begin{array}{l}\text { Individual and team work: The Capstone design process requires } \\
\text { contribution from the team members both as individuals and at the team } \\
\text { level. On their way to the design final goal, the students will learn first- } \\
\text { hand about the mechanisms necessary to establish and monitor their } \\
\text { team's organizational structure. They will learn how to promote team } \\
\text { effectiveness through individual action and to complete the team-based } \\
\text { project successfully. }\end{array}$ & $\begin{array}{l}\text { Letter of Intent, Progress Poster } \\
\text { Presentation, Final Team } \\
\text { Project Presentation }\end{array}$ \\
\hline 5 & $\begin{array}{l}\text { Communication skills: One of the most important phases of Capstone } \\
\text { projects is communication. Students will be identifying ways and } \\
\text { means to communicate engineering knowledge in the form of written } \\
\text { documentation and oral presentations, using iteration to emphasize key } \\
\text { points of learning, and reflection through effective use of log books. }\end{array}$ & $\begin{array}{l}\text { Letter of Intent, Progress Poster } \\
\text { Presentation, Final Team } \\
\text { Project Presentation, Group } \\
\text { Written Final Report, } \\
\text { Individual Professional } \\
\text { Conduct and Productivity }\end{array}$ \\
\hline 6 & $\begin{array}{l}\text { Professionalism: The Capstone project process requires everyone to } \\
\text { behave in a professional manner. While progressing through the } \\
\text { exercise, students will learn to describe engineering roles in a broader } \\
\text { context (e.g., as they pertain to the environment health, safety and } \\
\text { public welfare) and recognize the impacts of engineering within a } \\
\text { global society (i.e. the broader public interest). }\end{array}$ & $\begin{array}{l}\text { Group Written Final Report, } \\
\text { Peer Evaluation, Individual } \\
\text { Professional Conduct and } \\
\text { Productivity }\end{array}$ \\
\hline 7 & $\begin{array}{l}\text { Project management: Project management and economics are very } \\
\text { important part of engineering projects. While choosing the final design } \\
\text { from a set of candidate options, the students will learn to plan and } \\
\text { manage engineering activities within time and budget constraints. }\end{array}$ & $\begin{array}{l}\text { Letter of Intent, Group Written } \\
\text { Final Report }\end{array}$ \\
\hline 8 & $\begin{array}{l}\text { Lifelong learning: In addition to the knowledge gained through } \\
\text { completed course work, the students will learn to utilize research } \\
\text { resources (i.e. use of proper research databases to locate supporting } \\
\text { literature and cite these references in presentations and reports). They } \\
\text { will learn to independently summarize, analyze, synthesize, and } \\
\text { evaluate information from a wide variety of sources (learning } \\
\text { independently) and develop strategies to identify and address gaps in } \\
\text { knowledge (becoming a self-directed learner). }\end{array}$ & $\begin{array}{l}\text { Letter of Intent, Class/lecture } \\
\text { participation, Group Written } \\
\text { Progress Report, Group } \\
\text { Written Final Report }\end{array}$ \\
\hline
\end{tabular}


Proc. 2014 Canadian Engineering Education Association (CEEA14) Conf.

Table 2. Grading rubric for Progress Poster Presentation.

Assess the group's ability to:

\begin{tabular}{|l|l|l|l|}
\hline FAILS & MARGINAL & MEETS & EXCEEDS \\
\hline
\end{tabular}

\begin{tabular}{|l|l}
\hline DESIGN & 4a) Frame a complex, open-ended problem in
\end{tabular} engineering terms.

\begin{tabular}{|l|l}
\hline DESIGN & 4b) Generate a diverse set of candidate
\end{tabular} engineering design solutions.

DESIGN

4c) Select candidate engineering design solutions for further development.

DESIGN

4d) Make it clear that they are poised to advance an engineering design to a defined end state.

INIDIVIDUAL AND

6a) Establish and monitor team

TEAM WORK organizational structure.

INIDIVIDUAL AND

TEAM WORK

6b) Promote team effectiveness through individual action.

INIDIVIDUAL AND

TEAM WORK

6c) Make it clear that they will be able to successfully complete a team-based project.

COMMUNICATION

SKILLS

7a) Identify and credibly communicate engineering knowledge.

COMMUNICATION

SKILLS

7b) Demonstrate the ability to use different modes of communication.

COMMUNICATION

SKILLS

7c) Develop communication through an iterative process that involves reflection and self-guided learning.

Notes: 1. The rubric indicators in Table 2 were taken from the University of Toronto attribute tables posted on the EGAD website, http://egad.engineering.queensu.ca/?page_id=1207 [6].

2. The assessment criteria are as follows: FAILS -Not clear or concise -Much applicable information is missing;

MARGINAL -Somewhat clear and concise -Some applicable information is missing; MEETS -Somewhat clear and concise -All applicable information is present; and EXCEEDS -Clear and concise -All applicable information is present.

\section{RESULTS}

At the time of writing of this paper, the Winter 2014 offering of the MAME Capstone Design course was in session. The following data were compiled for the first two assessment tasks of the semester: the Letter of Intent and the Progress Poster Presentation.

With regard to the Letter of Intent task, each design team submitted a Letter of Intent for its project that included the project objectives, a list of team members and their assigned duties, anticipated deliverables, anticipated challenges, and a summary of the project budget.

The Letter of Intent assignment was chosen as the first task for the design teams because it requires teams to start planning not just what their final design will be, but also how they will organize their activities, time, and money to accomplish their goals.

Considering the CEAB GrAtts, the Letter of Intent assignment demonstrates the students' abilities in 
problem analysis, individual and team work, communication skills, economics and project management, and life-long learning. Using the Letter of Intent rubric, grades for these five GrAtts were assessed for each team. On average, each team's submission was graded by 4 evaluators made up of faculty and graduate assistants. A summary of the assessment results is shown in Fig. 1.

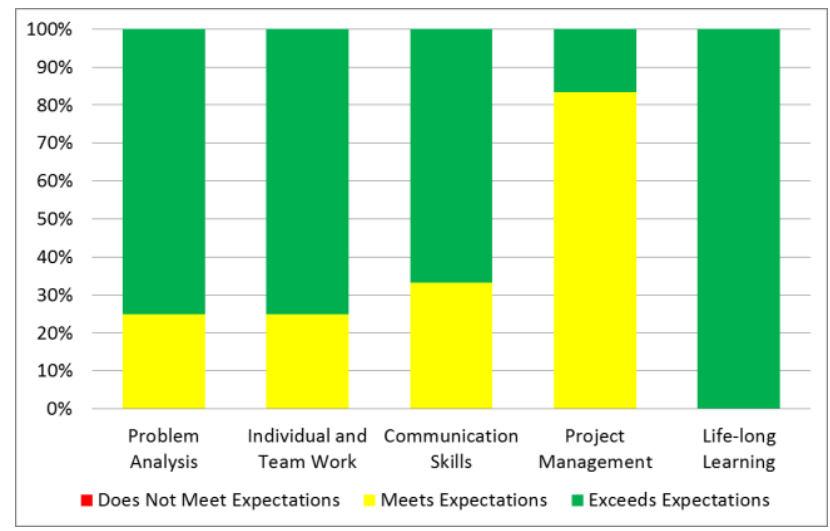

Fig. 1. LO achievement for the Letter of Intent assignment, for the following GrAtts: a) problem analysis, b) individual and team work, c) communication skills, d) economics and project management, and e) life-long learning. Numbers on the graph indicate how many of the student project groups were in each category.

With regard to the Progress Poster Presentation task, each design team designed and displayed a poster that described their progress at the end of the first semester, corresponding to the mid-way point of the course. On their poster, they were asked to include an introduction, project objectives, a description of their approach or methods, progress to date, and next steps toward completion of the project.

The posters were displayed in a common area of the Ed Lumley Centre for Engineering Innovation at the University of Windsor where departmental faculty, technologists, and graduate assistants viewed the posters and spoke to the project teams in order to complete the assessment.

Considering the CEAB GrAtts, the Progress Poster Presentation demonstrates the students' abilities in design, individual and team work, and communication skills. On average, each team's submission was graded by 10 evaluators made up of faculty, Mechanical Engineering technologists, and graduate assistants. Using the Letter of Intent grading rubric, grades for these three GrAtts were assessed for each team. A summary of the assessment results is shown in Fig. 2.

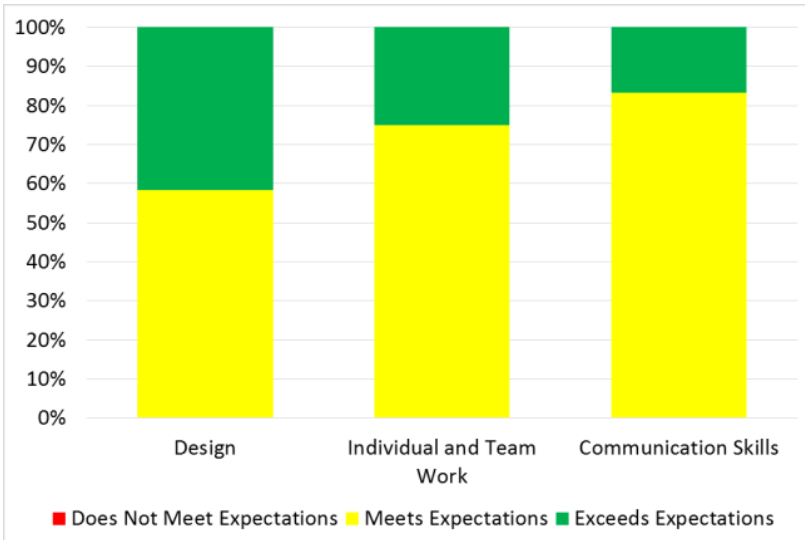

Fig. 2. LO achievement for the Progress Poster Presentation, for the following GrAtts: a) design, b) individual and team work, and c) communication skills. Numbers on the graph indicate how many of the student project groups were in each category.

\section{DISCUSSION}

In studying the Letter of Intent assessment data, it was observed that all teams met or exceeded expectations for all five of the measured GrAtts: problem analysis, individual and team work, communication skills, economics and project management, with all teams exceeding expectations for life-long learning. In summary, the class responded well to the challenge of explaining their Capstone Design projects at the outset of the course and presented a cohesive view of the expectations and challenges of the projects. In addition, each team's submission was clear about the extent to which they realize the necessity of continually learning beyond the curriculum to ensure the success of their work.

The results of the Progress Poster Presentation show a more modest result with all teams meeting or exceeding expectations for the three measured GrAtts: design, individual and team work, and communication skills. For this assessment, fewer teams exceeded expectations for the two GrAtts shared with the Letter of Intent submission (individual and team work, and communication skills). With the added ability to interview the students while reviewing their posters, it was likely that the assessment of these two GrAtts was more critical when the students were challenged to answer questions from such a wide variety of evaluators. It was apparent in some cases that the workload sharing in the team project may not have been as well-executed as initially planned in the Letter of Intent (as illustrated by the dominance of some of the team members in fielding questions). In general, the class is on track for achieving the course LOs as of the mid-point of the course, with no 
teams failing to at least meet the criteria for the measured GrAtts.

Feedback from the evaluators included the appropriateness of some of the sub-categories of the assessment rubric and quality of grammar in the documents. To address weaknesses in the ability of the rubric to capture the performance of each team on the task, the form will be revised before the next offering of the course to help streamline the process. Indeed, the rubric complexity was reduced from the first Letter of Intent assessment to the Progress Poster Presentation form. Weekly Capstone lecture schedules will be reviewed and modified to include timely material to support achievement of the Learning Outcomes in the future offerings of the course.

As was stated previously, the Winter 2014 offering of this course was in session at the time of writing of this paper. Initial feedback from the course coordinator regarding the usefulness and ease of assessing the LOs and GrAtts with the rubrics that were developed showed the following insights:

- Faculty are challenged to participate in assessing teams if they are not currently advising a team of their own, so ease in use of the forms is essential to increasing participation in the assessment processes.

- The time commitment of the coordinator is key to developing a seamless and simple process to managing the assessment data. As such, support from the faculty to assist in developing appropriate faculty-wide protocol and forms is necessary.

- The ability to determine a grade that is an accurate reflection of the quality of the work submitted must be kept at the forefront of the assessment to ensure that the processes developed are not applied without consideration of the nuance of individual project objectives.

- Inclusion of industry feedback on Capstone Design assessment is highly important, but because of differences in perspective on the importance of various project objectives, rubrics might have to be redesigned to ensure the appropriate metrics are in place.

\section{CONCLUSIONS}

Ensuring that students' performance in Capstone Design projects can be evaluated objectively and consistently is challenging due to factors such as industrial sponsorship (or lack thereof) and competition details and constraints. With twelve projects available to the current senior Mechanical Engineering students at the University of Windsor, we have created a common syllabus detailing common deliverables with common rubrics for assessment. This is the first year that the rubrics are being made available to all those willing and able to evaluate the students' performance. From the first two deliverables that we've examined in this paper, it is apparent that continuous improvement is a necessary part of the course curriculum development and the assessment methods employed to measure LO achievement.

\section{Acknowledgements}

The authors gratefully acknowledge the assistance and feedback from Dr. Tirupati Bolisetti for his application of the rubrics in his Civil and Environmental Engineering Capstone Design course as well as the University of Windsor for their financial support through the Academic Development Travel Fund.

\section{References}

[1] University of Windsor, "Fall 2014 Undergraduate Calendar," [Online]. Available:

http://web4.uwindsor.ca/units/registrar/calendars/und ergraduate/cur.nsf/Search+Main/9B72CA039C14A1 0585257364004C63B8?OpenDocument. [Accessed 21 May 2014].

[2] Organisation for Economic Co-operation and Development, "Assessment of Learning Outcomes in Higher Education: A Comparative Review of Selected Practices," OECD 2008, Paris, 2008.

[3] Engineers Canada, "Accreditation," Engineers Canada, [Online]. Available:

http://www.engineerscanada.ca/accreditation. [Accessed 4 February 2014].

[4] Engineers Canada, "Accreditation Criteria and Procedures 2013," Engineers Canada, Ottawa, 2013.

[5] S. M. Easa, "One-year Outcome-based Assessment at Ryerson University: Lessons and Best Practices," in Proceedings of the 2012 Canadian Engineering Education Association (CEEA12) Conference, Winnipeg, 2013.

[6] EGAD | Engineering Graduate Attribute Development, "Sample Cases | EGAD Project," 2011. [Online]. Available: http://egad.engineering.queensu.ca/?page_id=1207. [Accessed 13 April 2014]. 


\section{Author Information:}

Jacqueline Stagner, PhD, PEng: Dr. Stagner is the Undergraduate Programs Coordinator in the Faculty of Engineering, at the University of Windsor.
Jennifer Johrendt, PhD, PEng: Dr. Johrendt is an Associate Professor in the Mechanical, Automotive \& Materials Engineering Department, at the University of Windsor. 